\title{
Responding to the Call for Globalization in NuRsing EdUCATION: THE IMPLEMENTATION OF THE TRANSATLANTIC Double-Degree Program
}

\author{
CYNTHIA A. HORNBERGER, PHD, MBA, CNL, ARNP-CNS, ${ }^{*}$ \\ SIRKKA ERÄMAA, PHN, RN, LICED, † KORNÉLIA HELEMBAI, PHD, \\ PATRICK J. MCCARTAN, BSC (HONS), PHD, FFNMRCSI, RNT, RCNT, RGN, RMN, \\ AND TARJA TURTIAINEN, MNSC, RNII
}

\begin{abstract}
Increased demand for nurses worldwide has highlighted the need for a flexible nursing workforce eligible for licensure in multiple countries. Nursing's curricular innovation mirrors the call for reform within higher education including globalization of curricula (E. J. S. Hovenga, 2004; D. Nayyar, 2008; B. J. G. Wood, S. M. Tapsall, \& G. N. Soutar, 2005), increased opportunities for student mobility exchanges, dialogue between different academic traditions, and mutual understanding and transparency between universities (J. González \& R. Wagenaar, 2005). The European Union (EU) and United States have combined efforts to achieve these objectives by creating the Atlantis program in 2007 (U.S. Department of Education, 20I I). This article describes experiences of four nursing programs participating in an Atlantis project to develop a double-degree baccalaureate program for undergraduate nursing students. Early learnings include increasing awareness and appreciation of essential curricular and performance competencies of the baccalaureate-prepared professional nurse. Challenges include language competency; variations in curriculum, cultural norms, student expectations, and learning assessment; and philosophical differences regarding first-level professional nurse preparation as specialist versus generalist. The Transatlantic Double Degree program has successfully implemented the double-degree program. Members have gained valuable insights into key issues surrounding the creation of a more uniform, yet flexible, educational standard between our countries. (Index words: Globalization; Nursing education; Curriculum) J Prof Nurs 30:243-250, 2014. (C) 2014 Elsevier Inc. All rights reserved.
\end{abstract}

\footnotetext{
*Special Assistant to the President and Professor, former Dean, School of Nursing, Washburn University, Topeka, KS.

† Senior Lecturer, TADD-EU Coordinator, Mikkeli University of Applied Sciences, Mikkeli, Finland.

$\ddagger$ Head of Nursing Department, Department of Nursing, University of Szeged, Faculty of Health Sciences and Social Studies, Szeged, Hungary. §Senior Lecturer (Retired), School of Nursing and Midwifery, Queen's University Belfast, Northern Ireland, UK.

IISenior Lecturer, former Head of Department, Mikkeli University of Applied Sciences, Mikkeli, Finland.

Address correspondence to Dr. Hornberger: School of Nursing, Washburn University, Topeka, KS 66621. E-mail: cynthia.hornberger@washburn.edu 8755-7223
}

HE IMPLEMENTATION OF the Transatlantic
Double Degree (TADD) Program Health education
programs worldwide are responding to the call to develop
new models of education that meet the needs of rapidly
changing health care environments. In nursing, numer-
ous organizations have issued position statements
supported by research that call for transformation in
nursing education (American Association of Colleges of
Nursing [AACN], 2008; Benner, Sutphen, Leonard, \&
Day, 2009; Institute of Medicine [IOM], 2011). The
call for educational transformation is built upon
the evolving appreciation of nurses as knowledge 
workers who play a critical role in sustaining healthy communities (AACN, 2008; International Council of Nurses [ICN], 2004; ICN, 2006; IOM, 2011; National League for Nursing, 2005; Royal College of Nursing, 2007; World Health Organization, 2000). Increasingly professional nursing organizations recognize the trend of global nursing practice that requires first-level, professional nurses prepared at the baccalaureate or degree level (IOM, 2011).

The demand for nurses worldwide has highlighted the need for nurses who are eligible for licensure in countries other than their country of origin and education. The importance of such mobility and universal recognition of qualifications between countries and continents is inherent within the Bologna Declaration (1999). The Bologna Declaration acknowledged the need to reduce segmentation within the European higher education sector (History, n.d.). The Declaration outlined a process to create European Higher Education Area (EHEA; 2010), whose goal was to establish a wide and transparent range of high-quality courses, along with universally recognized procedures to foster student mobility and employability (History, n.d.). The longterm goal of the EHEA is to make education within Europe more compatible, comparable, and competitive to attract both students and scholars worldwide. Based on international cooperation and academic exchanges, the EHEA creates an attractive option for European students and staff as well as students and staff from other parts of the world.

The main Bologna reforms concentrated on the threecycle degree structure (bachelor, master, doctoral) and quality assurance in higher education. The Tuning Educational Structures in Europe project in 2000 connected the objectives of the Bologna Process to the higher educational sector. One author stated, "...Tuning is chosen...to reflect the idea that universities do not and should not look for uniformity in their degree programmes or any sort of unified, prescriptive or definitive European curricula but simply look for points of reference, convergences and common understanding" (Tuning Educational Structures in Europe, n.d.). The Tuning Project created the generic and subject-specific competencies; established the European Credit Transfer and Accumulation System (ECTS), which established course credit equivalencies; and promoted the quality enhancement of higher education process.

The Tuning Project has occurred in two phases. During the first phase, key educational subject stakeholders, to include faculty, students, graduates, and employers, developed a methodology to design and implement degree programs that met the objectives of the Bologna Declaration. During the second phase, numerous disciplines, including nursing, were evaluated using this methodology (González \& Wagenaar, 2005). Nursing was the first health care-related discipline to be evaluated within The Tuning Project. Generic and specific competencies for nursing graduates at the bachelor, master, and doctoral level were identified with subsequent improved understanding and comparability of different nursing curricula among countries (González \& Wagenaar, 2005). The Council of the European Union has invited Member States to further internationalize their activities by promoting the use of joint and double degrees to facilitate the recognition of graduates' subsequent qualifications for employment. For the purposes of this article, the definitions proposed by Obst and Kuder (2009, p. xvi) are used:

A joint degree program: students study at (at least) two higher education institutions and receive upon completion of the study program a single-degree certificate issued and jointly signed participating institutions.

A double-degree program: students study at (at least) two higher education institutions and receive upon completion of the study program a separate degree certificate from each of the participating institutions.

To describe the features of transatlantic degree programs, Obst and Kuder (2009), conducted a survey of higher education institutions from the European Union (EU), the United States and other non-EU countries in Europe. A total of 180 institutions responded with 51\% (92) representing the $\mathrm{EU}, 45 \%$ (81) representing the United States, and 4\% (7) representing non-EU countries. Further analyses excluded the seven responses from nonEU countries. The survey found that double degrees were much more common among the participating institutions. Twenty-six percent of EU institutions offered joint degrees and $76 \%$ offered double degrees. In the United States, $13 \%$ offered joint degrees, whereas $68 \%$ offered double degrees. In general, joint degrees are considered more complex because of the requirement of two institutions agreeing upon a complete curriculum that meets institutional and regulatory requirements (Obst \& Kuder, 2009). Double degrees offer the opportunity to obtain the required competencies within each country, albeit at a slightly higher cost. This cost, however, is generally lower than the cost to obtain each degree separately from the two institutions. Similarly, these programs offer completion of the joint or double degree in less time than if done separately. Both types of degree programs would provide students with options for employability in the institutions' country.

Most recently, the National Council of State Boards of Nursing, Inc. completed a comparison of the weighting provided by nurses from the United States and the UK on international nursing educational competencies compiled during the tuning process (De Bruin, Christian, Wegewijs, et al., 2007). What they found was encouraging in that nurses in both countries found the competencies relevant for practice.

\section{Background}

Nursing's call for innovation mirrors the call for reform within higher education. A key element of this reform is a targeted focus on globalization of curricula (Hovenga, 2004; Nayyar, 2008; Wood, Tapsall, \& Soutar, 2005) 
created through increased internationalization efforts such as expanded student mobility exchanges and use of technology to share international educational experiences. As academic dialogue about different educational traditions continues, there is enhanced mutual understanding and transparency between universities (González \& Wagenaar, 2005). Internationalization is defined as "the process of integrating an international, intercultural, or global dimension into the purpose, functions, or delivery of postsecondary education (Knight, 2003, p. 2). Expanding use of technology allows for more participation of all faculty and students within these international collaborations, both those studying abroad and those remaining at home (Knight, 2004).

Historically, the rationales for internationalization included national and institutional perspectives. Nationally, there are positive sociocultural, economic, and geopolitical reasons for expanding educational international initiatives. Institutionally, the competitive branding potential of international education has been recognized with subsequent acceleration of curricular innovations that streamline global workforce development.

Qiang (2003) identified several common approaches to achieving institutional internationalization, including the following:

1. Activity approach-promotes individualistic activities such as faculty/student exchanges, curricular revision, and increased international student recruitment.

2. Competency approach-focuses on achievement of competencies that reflect enhanced international knowledge and skills.

3. Ethos approach-aims to create institutional cultures that value diversity and appreciate the future importance of international knowledge, and

4. Process approach-establishes policy and procedures that sustain internalization through revised teaching, scholarship, and service standards.

One benefit of using these approaches within nursing education is the enhanced cultural competence of the nurse graduate. In Giger and Davidhizar (2002, p. 187), cultural competence connotes "a higher, more sophisticated level of refinement of cognitive skills and psychomotor skills, attitudes, and personal beliefs." Nursing has embraced the responsibility to address cultural competence domestically and is now poised to extend these competencies globally.

\section{Atlantis Program}

Recognizing the importance of internationalizing higher education, the EU and United States have jointly combined efforts to support the Atlantis program since 2007 (U.S. Department of Education [USDE], 2011). This program supports the creation of "consortia of higher education and training institutions working together at undergraduate or graduate levels to improve their educational services, to compare and modernize curricula and to develop joint study programs with full recognition of credits and qualifications" (Education, Audiovisual and Culture Executive Agency [EACEA], 2011). The program, jointly administered and funded by the USDE and the European Commission's Directorate General for Education and Culture, "provided grants for four to five years to add a European Community-United States dimension to international curriculum development and related student exchange" (USDE, 2011). Atlantis was originally administered in the United States by the Fund for the Improvement of Postsecondary Education (FIPSE) and now is administered by the International and Foreign Language Education Service, and by the EACEA in Europe. In the report commissioned by the Atlantis Program, Obst and Kuder (2009) found that most respondents indicated interest in developing such programs, but cited barriers including insufficient financial support and accreditation constraints. Cost issues were greater for American students who more often assumed personally the increased cost of studying abroad.

The Atlantis program requires proposals to include at least one U.S. and two EU institutions of higher education. Projects must include "organizational frameworks for transatlantic student mobility, including work placements and internships that will provide adequate language preparation and full academic credit" (USDE, 2011). To date, 81 proposals have been funded in the 4 years of the program, including a wide variety of educational specialties. Of the 81 proposals, 2 involve nursing programs in the United States, Finland, Northern Ireland, and Hungary. Unfortunately, the program will no longer receive funding for new proposals that were to be accepted for the remaining 3 years of the agreement (USDE, 2011). The purpose of this article is to describe the experiences of the nursing programs participating in one of the funded Atlantis proposals and to highlight early outcomes and insights.

\section{Transatlantic Double Degree Program}

In 2009, four schools of nursing were notified that their TADD grant proposal had been selected by FIPSE and EACEA for funding for the next 4 years. The four schools participating in the grant are Washburn University (WU), Mikkeli University of Applied Sciences (MUAS), the University of Szeged (USZ), and Queens University Belfast (QUB).

WU was founded in 1865 in the US state of Kansas. Four schools in business, applied studies, law, and nursing and the College of Arts and Sciences offer studies in more than 200 undergraduate major, certificate, and graduate programs for 7,200 students. The School of Nursing began in 1974 and offers bachelor of science in nursing (BSN), master of science in nursing, and doctor of nursing practice degree programs. The length of the 124 credit hour based (248 ECTs) BSN consists of four academic years. Every year, 150 students complete their BS in nursing degree. 
MUAS is a multidisciplinary higher education institution in Finland offering high-quality education, research and development activities, and international projects with 200 partners. MUAS has 4,500 students and offers 22 bachelor degree programs, 9 master degree programs, and 3 double-degree programs. The health care education programs began in 1955 with the Department of Health Care offering bachelor of science (BSc) degree programs in nursing, physiotherapy, podiatry and a master's degree program in health care. The length of the credit based (210 ECTs) BSc consists of three and one-half academic years. Every year, 70 students complete their BSc in nursing degree.

The USZ was founded in 1581 in Hungary. At present, the 12 faculties have nearly 30,000 students, 1,000 of them from foreign countries. The first nursing department devoted to the higher education in Hungary was established in 1993 at the Faculty of Health Sciences and Social Studies. The length of the credit based (240 ECTs) BSc consists of four academic years. Every year, 100 to 110 correspondent and regular students complete their BSc in nursing in two languages, Hungarian and English.

Founded in 1845 in Northern Ireland, QUB has three faculties containing a total of 20 schools. With more than 19,000 students from over 80 countries, QUB provides a wide range of both undergraduate and postgraduate degree programs. The School of Nursing and Midwifery was created in 1991 and offers seven honors degree programs, two master degree programs, and three doctorate programs. The credit based (270 ECTs) BSc (Hons) in Health Studies degree, offered within the TADD program, consists of three calendar years, including summer semesters. Every year, approximately 50 students graduate with a BSc (Hons) in Health Studies degree.

Three of the four schools had worked together previously on a FIPSE-EU-funded grant to establish the Community Health Networking Project from 1997 to 2000. In that project, the schools of nursing, together with other grant partners, created a community health module and then supported short-term student mobility exchanges over a 3-year period to offer students and faculty a transatlantic opportunity to learn about nursing in another country. On the basis of the positive experiences of this program and ongoing collegial relationships, three of the program administrators, along with the administrator of a fourth nursing program, supported the design of the TADD program. It was deemed more feasible to begin this collaboration with a double-degree program, rather than joint degree. This approach would offer more flexibility to maintain unique curriculum and regulatory requirements of each institution and provide immediate recognition of countryspecific credentials required for professional practice for the TADD graduates.

The development of the TADD proposal involved face-to-face and virtual meetings of the partners over a 3-year period. The partners shared a philosophical viewpoint of professional nurses requiring a baccalau- reate degree. Three programs could provide a BSN degree, and one provided a bachelor of health sciences to the international students. Many issues did surface, however, in the discussion of creating a double-degree program that offered students true mobility between countries upon graduation with their dual degrees. Significant issues included regulatory and policy constraints, university admission and graduation requirements, and curricular differences. Regulatory and policy issues focused on eligibility for licensure or registration within each country. Admission and graduation requirements included the adequate provision of language instruction before and during the student mobility exchanges. Numerous curricular issues arose, including differences in (a) weighting of didactic and clinical practice within the overall curriculum, (b) evaluation methods, (c) grading scales, and (d) credit hour calculations.

The final project outlined an ambitious program to provide an academic year (9 to 12 months) of instruction in four core modules of Ethical and Legal Implications for Nursing, Nursing Leadership, Community/Public Health Nursing, and Nursing Research/ Evidence-based Practice; plus language/culture courses, partner-specific courses, and additional courses to meet university-specific graduation requirements. The program of study required an additional one or two semesters, depending on the particular institution. The additional time and credit hour requirements met the overall stipulations of the Atlantis program in that students could complete two degrees in less time and cost of two separate degree programs. A key objective of the grant was, at the completion of required studies at both the home institution and the partner institutions, to receive baccalaureate degrees from the home institution and from one of the partner institutions.

The grant provided for 24 U.S. students and $24 \mathrm{EU}$ students (8 from each EU partner school) to participate in the student mobility. In addition, 27 faculty (9 from the United States, 6 from each EU partner school) would travel abroad to teach in one of the core modules that had been created cooperatively. All courses taken by TADD students would be taught in English. Annual team meetings would review and evaluate project outcomes. Ongoing innovation would be supported through use of technology, including Internet-based course management and communication sharing software. Project results would be shared through publication of manuscripts and professional presentations.

Grant awards were funded separately for the United States and EU. The U.S. grant totaled $\$ 420,000$, of which $\$ 288,000$ was for student mobility stipends. Each U.S. student receives approximately $\$ 12,000$ to cover housing and travel costs. Of the remaining $\$ 132,000$, $\$ 37,200$ was budgeted for personnel, $\$ 60,000$ for faculty travel, $\$ 12,000$ for external evaluator consultation, with the rest for supplies and indirect costs. The total grant of EU is $408,000 €$, of which $288,000 €$ is for student mobility, $60,000 €$ for faculty mobility, and 
$60,000 €$ for administrative costs. Each EU student can receive $12,000 €$.

The objectives of the TADD program include general, specific, and operational objectives. The general objective of the grant is to prepare student nurses for more universal practice in the EU and United States. Students and faculty will build new competencies in languages, cultural understanding, and use of technology in the delivery of primary and population-based health care to diverse populations. Although not a primary objective of the grant, the partners did acknowledge the value of preparing graduates able to practice in another country. In three of the partner universities, students who complete their degrees will be eligible for licensure or registry as nurses upon (a) recommendation of the university and (b) achievement of language requirements, and in the United States, (c) successful completion of the National Council Licensure Examination-Registered Nurse (NCLEX-RN). In the UK, additional didactic instruction related to their specific health care system and additional clinical practice may be required as determined through review by the National Midwifery Council.

\section{Specific Objectives}

1. Establish and evaluate a recognized and accredited undergraduate double-degree program in nursing in cooperation with the four participant universities.

2. Expand higher education institutions' and faculties' skills in international education and network development.

3. Enhance students' personal and professional growth by offering transatlantic mobility with a focus on culture and language studies, profes-

Table I. Operational Objectives of the TADD program

Ia. Compare curricula and its philosophical and pedagogical foundations in grant partners' programs.

Ib. Create a thoughtful plan for curricular conversion between ECTS, Credit Accumulation and Transfer Scheme (CATS), and credit systems of the four universities to establish equitable workload patterns for nursing students.

Ic. Develop use of the Diploma Supplement for TADD.

2a. Develop common core curriculum based on existing courses within partners' curricula. Common learning outcomes will guide the content, methodology, use of teaching and learning technologies, and evaluation processes.

2b. Implement pilot study program. And then evaluate and improve according to experiences and systematic feedback.

3a. Students will possess sufficient language and cultural competence to provide nursing and population-based care.

$3 b$. Students prepared as leaders to influence care using evidencebased practice.

4a. Faculty will create with students' new learning opportunities reflecting intercultural awareness in practice. sional nursing leadership, research and evidencebased nursing.

4. Expand faculty worldview as they develop international programs and attain the skills needed to implement TADD.

Specific operational objectives are provided in Table 1.

\section{Evaluation}

An evaluation matrix (see Table 2) was created to evaluate each of the project objectives from the view of the outcomes of student learning, faculty enrichment, and program effectiveness. Evaluation strategies include the collection of quantitative and qualitative data from both students and faculty across the four partner universities, using a methodological triangulation approach involving surveys, student portfolios, and interviews. An external evaluator was hired to provide expertise in the development and ongoing monitoring of the evaluation process.

\section{Implementation}

The first cohort of students participating in the TADD program began their student exchanges in August 2010. These students completed the study abroad year and returned to their university of origin to complete final degree requirements or to graduate. The original eight students included three students from WU who studied in MUAS for 2 months and then spent 9 months at QUB. Two of these students have now graduated and have received their degrees from both universities. Of the five EU students, one has now completed their EU degree and received their WU degree. Two more EU students will complete their degrees later this year and subsequently be eligible for the U.S. degree, with the remaining two completing next year. The second cohort began in August 2011, with five U.S. students and six EU students. Two U.S. students completed studies at MUAS and USZ, with the other three U.S. students completing studies at QUB and USZ. The six EU students remained at WU throughout the academic year. Since initial notification of the grant award in August 2009, faculty have developed core modules, traveled abroad to teach in the core modules, provided instruction to visiting international students, attended onsite international planning sessions, and participated in monthly video teleconferences. To date, six U.S. faculty and nine EU faculty have traveled abroad to provide academic instruction at other partner institutions.

\section{Initial Outcomes}

Two years after grant implementation, initial outcomes related to meeting the specific objectives include the following:

1. Establish a recognized and accredited undergraduate double-degree program in nursing.

a. Degree programs are now established with two U.S. TADD program graduates having obtained double degrees. Both U.S. students 
Table 2. Evaluation Matrix

\begin{tabular}{|c|c|c|c|}
\hline Project objectives & $\begin{array}{l}\text { Measurement } \\
\text { instruments }\end{array}$ & $\begin{array}{c}\text { Type of } \\
\text { assessment }\end{array}$ & $\begin{array}{l}\text { Appropriate to } \\
\text { gauging success }\end{array}$ \\
\hline \multicolumn{4}{|l|}{ Student learning } \\
\hline \multirow{4}{*}{$\begin{array}{l}\text { I.I Gain international } \\
\text { personal and professional } \\
\text { experience }\end{array}$} & a. Course grades & a. Knowledge/skills & $\begin{array}{l}\text { a. Course grades reflect academic } \\
\text { achievement in the content }\end{array}$ \\
\hline & b. Practicum evaluations & b. Knowledge/skills & $\begin{array}{l}\text { b. Practicum evaluations match the } \\
\text { course objectives and completed } \\
\text { by instructor }\end{array}$ \\
\hline & c. Reflective portfolio rubric & c. Attitude/behavior & $\begin{array}{l}\text { c. Rubric is used to analyze } \\
\text { reflective portfolio for } \\
\text { qualitative analysis }\end{array}$ \\
\hline & d. Cultural competence survey & d. Attitude & $\begin{array}{l}\text { d. Survey reflects students' } \\
\text { cultural competence or } \\
\text { lack thereof }\end{array}$ \\
\hline $\begin{array}{l}\text { 1.2 Attain double degree } \\
\text { in less time than to obtain }\end{array}$ & $\begin{array}{l}\text { a. Number of } \\
\text { months to complete degree }\end{array}$ & a. Knowledge/skills/behavior & $\begin{array}{l}\text { a. Responds to Project } \\
\text { Objective } 1.2\end{array}$ \\
\hline two separate degrees & b. Identify graduates of TADD & b. Knowledge/skills/behavior & $\begin{array}{l}\text { b. Responds to Project } \\
\text { Objective } 1.2\end{array}$ \\
\hline \multirow[t]{3}{*}{$\begin{array}{l}\text { I.3 Develop foreign language } \\
\text { skills for professional practice }\end{array}$} & $\begin{array}{l}\text { a. Language skills tests } \\
\text { (TOEFL/US) }\end{array}$ & a. Knowledge/skills & $\begin{array}{l}\text { a. Will determine English } \\
\text { proficiency for EU students } \\
\text { and intensive English } \\
\text { class placement }\end{array}$ \\
\hline & $\begin{array}{l}\text { b. Grades from language } \\
\text { courses in Finland and Hungary }\end{array}$ & b. Knowledge/skills & $\begin{array}{l}\text { b. Reflects language proficiency } \\
\text { for students }\end{array}$ \\
\hline & $\begin{array}{l}\text { c. Poster presentation } \\
\text { in target language }\end{array}$ & c. Knowledge/skills & $\begin{array}{l}\text { c. Authentic assessment of } \\
\text { target language }\end{array}$ \\
\hline $\begin{array}{l}\text { I.4 Share experiences reflecting } \\
\text { the health care specializations } \\
\text { within partner institutions }\end{array}$ & $\begin{array}{l}\text { a. Exit interviews and debriefing } \\
\text { b. Presentations at } \\
\text { professional conferences }\end{array}$ & a. Knowledge/skills & $\begin{array}{l}\text { a. Authentic assessment of } \\
\text { knowledge gained in TADD } \\
\text { program }\end{array}$ \\
\hline $\begin{array}{l}\text { I.5 Develop leadership skills } \\
\text { using evidence-based practice }\end{array}$ & $\begin{array}{l}\text { a. Bachelor thesis } \\
\text { completion/final research } \\
\text { project criteria }\end{array}$ & a. Knowledge/skills/behavior & $\begin{array}{l}\text { a. Requires evidence-based } \\
\text { project and leadership skills to } \\
\text { complete both project and thesis }\end{array}$ \\
\hline
\end{tabular}

were successful in passing NCLEX-RN the first time.

b. Positive first- and second-year reviews were received from FIPSE and EACEA.

c. Three EU students will receive their U.S. degrees in 2012. Some are interested in taking NCLEX and considering U.S. employment.

2. Expand institutions' and faculties' skills in international education and network development.

a. Faculty have established relationships within partner institutions and continue to make pedagogical and curricular adaptations to enhance students' experiences and learning achievement.

b. Module leaders from each partner university are now identified and are engaged in academic dialogue via email and videoconferences.

c. Language competency assessment has become more streamlined. The U.S. Intensive English instructor has worked closely with coordinators in MUAS and USZ to clarify language assessment techniques in these countries.

d. WU students participate in video teleconferences with MUAS to present community health assignments.
3. Enhancestudents' personal and professional growth. a. Reports from the first and second year cohorts were positive during exit interviews. Observations included differences in the pacing of courses and assessment methods (e.g., papers versus multiple-choice examinations), the challenges of learning a second language, and satisfaction with successfully navigating another country's educational, health care, transportation, and social systems.

b. Students from home institutions have had many opportunities to interact with TADD students in the classroom and through extracurricular activities.

c. Early evidence of enhanced cultural competence is being demonstrated in the final semester performance of returning TADD students. Students expressed experiencing transformation in their perceptions of other cultures through their immersion experiences. Other evidence included demonstrating (a) basic competency in another language, (b) ability to adapt to international nursing care environments,(c) an expressed broader 
view of global nursing, (d) successful mastery of courses taught pedagogically differently in other countries, and (e) application of acquired experiential knowledge to their personal and professional lives.

4. Expand faculty worldview.

a. A total of 12 U.S. and 20 EU faculty have participated in TADD as visiting lecturers, project coordinators, and core module instructors in home institutions.

b. Areas of expanded understanding thus far include learning about different learning and language assessment methods, grading scales, and curriculum formats such as modular versus semester sequencing, and varying philosophies of clinical instruction.

c. Numerous faculty have participated in curricular and extracurricular activities with TADD students and visiting faculty.

\section{Early Implementation Insights}

At the completion of the first and second years of student exchanges, the TADD core team of administrators, program directors, and lead faculty and staff met in person to review the program implementation and early outcomes. Early insights have been used to make ongoing improvements in the program and include the following:

1. Language competency remains a challenge. Much improvement was seen in the processing of the second cohort in regards to assessment and placement in Intensive English courses. For U.S. students traveling to the $\mathrm{EU}$, basic language preparation in Hungarian and Finnish included offering an onsite summer language course and use of electronic language resources. While at MUAS and USZ, additional language instruction is provided to assist students in meeting institutional language competency standards. Students report enjoying the opportunity to learn and use a second language. For the third year, assessment of language proficiency will be completed after students are selected so that language instruction can begin while still at their home institution.

2. Communication between schools is critical and requires a great deal of creativity and diligence to make sure all partners understand each other's curriculum, cultural norms, and expectations. Partner schools are now participating in monthly Internet-based conference calls to share projectrelated information. The use of Moodle as a course management software is expanding.

3. Description of programs must be clearer and provide an easily understood categorization of course content. Team members continue to share information about course content, evaluation strategies, and agreed to change the grade scale matrix to better reflect the actual perfor- mance assessment expectations of the faculty.

4. Methods of evaluation within courses are substantially different between the EU and the United States. We will continue to work on evolving toward a more hybridized approach to student assessment that reflects the best elements of both traditions. Partners have adjusted course-level evaluation methods to reflect content mastery, rather than using only multiplechoice testing skill.

5. Philosophical differences remain in regards to nursing as an applied or primary science. In the United States and Hungary, nursing education is built upon 2 years of general education and prerequisite science courses taught after secondary school completion. Conversely, within the UK, all general education subjects, including the mandatory sciences biology and chemistry, are studied at secondary school level. Within the 3-year university nursing program, the science subjects are further developed and applied to the study of nursing. Finland has a competencebased nursing curriculum, which is built on nursing science, and other multidisciplinary knowledge such as medicine, psychology, sociology, and cultural science, which have been integrated to the professional studies. In Finland, the general education and the prerequisite science courses have been studied at the secondary education level (in high school or vocational school).

6. Hours of clinical practicum required. The EU requires 2,300 clinical practicum hours, while U. S. programs often require significantly less hours.

7. Preparation of the professional nurse as a specialist versus a generalist. Registered nurses in the UK are prepared as specialists, whereas the other two EU and U.S. graduates are prepared as generalists. Discussions are ongoing about this major difference between programs.

\section{Summary and Conclusions}

The TADD program has experienced success in its first 2 years of implementation. We are increasingly aware of the challenges of creating a more uniform, yet flexible, educational standard between our countries. Yet, we are energized by the positive feedback of the first cohort of students and faculty who have been transformed by their experiences. We are experimenting with many of the approaches identified by Qiang (2003) to achieve institutional internationalization, believing these strategies represent a continuum of understanding. Each of our schools had previously participated in the activity approach to internationalization. Through the TADD project, we are now using the competency approach to develop the skills, knowledge, attitudes, and values in students, faculty, and staff. As a result, we have created a culture that values and supports international 
intercultural perspectives: the ethos approach. Over time, these experiences will hopefully lead to elements of the process approach, which stresses the integration of the international dimension into all areas of academe: teaching, scholarship, and service.

As partners, we believe one of the most significant outcomes of this project is the increasing appreciation for each other's educational viewpoint of what constitutes essential curricular and performance competencies of the baccalaureate-prepared professional nurse. Recognizing the tremendous learning that is occurring, it is the expressed hope of all partners to continue to offer the double degree after the completion of the TADD project. We will incorporate the best of what we have learned to offer a more streamlined educational experience. The length of the exchange period may be shortened by offering core courses on-line. To further reduce the financial burden, new sources of funding will be sought to support students' travel expenses In addition to sustaining the baccalaureate double degree, the schools have begun discussing the development of an international joint master's degree program.

These early outcomes and insights will guide our continued efforts to create an internationalized higher education pathway for culturally competent, globally aware, professional nurses. We look forward to the upcoming years as we continue to achieve the goals of the TADD project and beyond.

\section{References}

American Association of Colleges of Nursing. (2008). The essentials of baccalaureate education for professional nursing practice. Washington, DC: Author. Retrieved at https://www. aacn.nche.edu/Education/pdf/BaccEssentials08.pdf.

Audiovisual and Culture Executive Agency (EACEA). (2011). Bilateral cooperation in the field of higher education: About EU-USA Atlantis programme. Retrieved at http://eacea.ec.europa.eu/ bilateral_cooperation/eu_us/programme/about_eu_usa_en.php.

Benner, P., Sutphen, M., Leonard, V., \& Day, L. (2009). Educating nurses: A call for radical transformation. San Francisco: Jossey-Bass Education.

De Bruin, L., Christian, A. M., \& Wegewijs, B. (2007). Competencies in education and cross-border recognition: Evaluation of the usefulness of learning outcomes and competencies for international recognition. Retrieved at http://www.ihep.org/ assets/files/gcfp-files/CoRe_Evaluation.pdf.

European Higher Education Area. (2010). Budapest -Vienna Declaration on the European Higher Education Area. Retrieved at http://www.ond.vlaanderen.be/hogeronderwijs/bologna/ 2010_conference/documents/Budapest-Vienna_Declaration.pdf.

Giger, J. N., \& Davidhizar, R. E. (2002). The Giger and Davidhizar transcultural assessment model. Journal of Transcultural Nursing, 13, 185-188.
González, J., \& Wagenaar, R. (2005). Tuning educational structures in Europe II. Universities' contribution to the Bologna process. Retrieved at http://www.tuning.unideusto.org.

History. (n.d.). Bologna Process - European Higher Education Area. Retrieved from http://www.ehea.info/article-details. aspx? ArticleId=3.

Hovenga, E. J. S. (2004). Globalisation of health and medical informatics education-What are the issues? International Journal of Medical Informatics, 73, 101-109.

International Council of Nurses (2004). Scope of nursing practice (position statement). Geneva: Author. Retrieved at http://www.icn.ch/images/stories/documents/publications/ position_statements/B07_Scope_Nsg_Practice.pdf.

International Council of Nurses (2006). Continuing competence as a professional responsibility and public right (position statement). Geneva: Author. Retrieved at http://www.icn.ch/ images/stories/documents/publications/position_statements/ B02_Continuing_Competence.pdf.

Institute of Medicine (2011). The future of nursing: Leading change, advancing health. Retrieved at http://www.nap.edu/ catalog.php?record_id=12956.

Knight, J. (2003). Updated internationalization definition. International Higher Education, 33, 2-3.

Knight, J. (2004). Internalization remodeled: Definition, approaches, and rationales. Journal of Studies in International Education, 8, 5-31 http://dx.doi.org/10.1177/1028315303260832.

National League for Nursing. (2005). Transforming nursing education (position statement). New York: Author. Retrieved at http://www.nln.org/aboutnln/PositionStatements/transforming 052005.pdf.

Nayyar, D. (2008). Globalisation: What does it mean for higher education? In L. E. Weber, \& J. J. Duderstadt (Eds.). The globalisation of higher education. (pp. 3-14). London, UK: Glion Colloquium Series.

Obst, D., \& Kuder, M. (2009). Joint and dual degree programs in the transatlantic context: A survey report. In D. Obst, \& M. Kuder (Eds.). Joint and double degree programs: An emerging model for transatlantic exchange. (pp. 1-17). Berlin: Institute of International Education.

Qiang, Z. (2003). Internationalization of higher education: Towards a conceptual framework. Policy Futures in Education, 1, 248-270.

Royal College of Nursing. (2007). Nurses as partners in delivering public health. London: Author.

Tuning Educational Structures in Europe. (n.d.). Retrieved at http://www.unideusto.org/tuningeu/.

U.S. Department of Education. (2011). Purpose of Atlantis program. Retrieved at http://www2.ed.gov/programs/fipseed/ index.html.

Wood, B. J. G., Tapsall, S. M., \& Soutar, G. N. (2005). Borderless education: Some implications for management. International Journal of Educational Management, 19, 428-436.

World Health Organization. (2000). Munich declaration. Nurses and midwives: A force for health, 2000. Copenhagen: Author. Regional Office for Europe. Retrieved at http://www. euro.who.int/_data/assets/pdf_file/0007/53854/E93016.pdf. 